\title{
Quarantine and isolation nurses conditions during COVID-19 in Jeddah City
}

\author{
Shafeah M. Aljedaani* \\ Nursing Administration in Jeddah City, Directorate of Health Affairs, Ministry of Health, Kingdom of Saudi Arabia
}

Received: June 1, 2020

DOI: $10.5430 /$ jnep.v10n10p90
Accepted: June 27, 2020

URL: https://doi.org/10.5430/jnep.v10n10p90

\begin{abstract}
Background: The novel coronavirus is a pandemic respiratory disease that spreads from person to person. As the outbreak continues to develop, several countries have taken measures to prevent the transmission of the disease. Some of these measures are quarantine and isolation. Nurses are on the front line of the health care system during the COVID-19 outbreak, and they may become overwhelmed by the numerous pressures, such as the risk of infection, inadequate supplies, workload, and frustration. The aim of this study is to identify nurses' conditions in quarantine and isolation during the COVID-19 outbreak in Jeddah city. Methods: A cross-sectional descriptive design, a questionnaire was used for data collection.

Results: About $60 \%$ of the participants were willing to continue working in quarantine and isolation. The main reasons they were willing to continue were a safe working environment (37.3\%) and effective teamwork (31.8\%), while the main reasons that made the participants unwilling to continue were the lack of rewards and incentives (28.3\%), and an unsafe work environment (40.0\%). Regarding the nurses' assessment of quarantine and isolation conditions during the COVID-19, most participants confirmed that they often choose a positive element. This study found a significant difference according to the current place of work, which was positive on the side of the nurses who are working in quarantine.

Conclusions: This study's findings provide important recommendations related to the improvement of quarantine and isolation conditions, staff nurses' conditions, and disease-outbreak-related readiness. It is hoped that these recommendations will contribute to enhance the current and future conditions of nurses in isolation and quarantine.
\end{abstract}

Key Words: Nursing, Quarantine, Isolation, Conditions

\section{INTRODUCTION}

COVID-19 is the novel pandemic coronavirus disease spreading from person-to-person and has led to a serious public health problem. COVID-19 can cause mild to severe respiratory illness. The severest illness happens in older people. ${ }^{[1]}$

By May 19, 2020, around 4,731,458 COVID-19 cases were confirmed worldwide, including 59,854 in Saudi Arabia. ${ }^{[2]}$ As the outbreak continues to evolve, planning to prevent the spread of COVID-19 is critical for countries to maintain health care services during the ongoing pandemic. ${ }^{[3]}$ Some countries have taken measures to prevent transmission of the disease to new areas or to decrease human-to-human transmission in areas where the virus that causes COVID-19 is widespread. $^{[4]}$ Some of the measures to accomplish these goals may consist of quarantine and isolation, which include the restriction of movement or separating people who may have been suspected or confirmed of COVID-19. The objective is to care for and monitor their symptoms, ensuring early detection of cases and preventing transmission of the virus

\footnotetext{
*Correspondence: Shafeah M. Aljedaani; Email: Shamj2014@ gmail.com; Address: Nursing Administration in Jeddah City, Directorate of Health Affairs, Ministry of Health, Kingdom of Saudi Arabia.
} 
to the rest of the population. ${ }^{[1,4]}$

Quarantine is one of the oldest and most effective tools for controlling an infectious disease outbreak. ${ }^{[5]}$ Quarantine is defined as "the restriction of persons who are presumed to have been exposed to COVID-19 but are not ill," quarantine may be voluntary or mandatory and applied at the individual, group, or community level, and it usually involves restriction to the home or a designated facility, while isolation is defined as "the separation of ill persons with contagious diseases". ${ }^{6]}$

Health care providers in quarantine and isolation face enormous pressure, including the risk of infection, inadequate personal protective equipment (PPE), discrimination, work overload, frustration, isolation, patients with negative feelings, lack of contact with their families, and exhaustion. Their work in quarantine and isolation for prolonged periods can cause mental health problems such as stress, anxiety, depression, restlessness, anger, and distress, in addition to negative impacts on their understanding and decision-making capability, which might negatively affect their desire to fight against COVID-19. ${ }^{[7,8]}$

As for health care providers, the unfamiliar nature of the virus, inadequate testing, limited treatment options, insufficient PPE and other medical supplies, extended workloads, and other emerging concerns are sources of stress and have the potential to overwhelm systems. ${ }^{[9]}$

Health care providers are the most significant resource in the health care system. They deserve attention and to have their opinions taken into consideration. Health care providers should ensure that they are well trained, equipped, and capable of the practices needed to prevent the spread of respiratory diseases like COVID-19 within the facility, promptly identify and isolate patients with possible COVID-19, and inform the correct facility staff and public health authorities. ${ }^{[1,3,4]}$

In the same line, Lee et al. ${ }^{[10]}$ found that health care providers who delivered care to Middle East respiratory syndrome patients were at a massive risk of displaying symptoms of post-traumatic stress disorder even after time had elapsed. Authors of another study during the H1N1 influenza outbreak indicated that a significant percentage of health care providers suffered moderately high levels of worry, and the degree of worry was correlated to psychological distress. ${ }^{[11]}$

Nurses are the frontline health care providers, and they may become overwhelmed by issues that may affect them while facing the COVID-19 pandemic. This is due to the infectious disease's unpredictable nature. Unknown and fastdeveloping pathological characteristics of some microorganisms are sometimes difficult to treat and may lead to panic, chaos, and lack of personal safety. Nurses who may experi-

Published by Sciedu Press ence high levels of anxiety and stress outbreaks will have to care for patients with this disease. ${ }^{[12]}$ It is necessary to pay attention to protect nurses during the COVID-19 outbreak. Nurses are expected to work long hours under significant pressure with often insufficient resources, while accepting the risks innate in close communication with ill patients. Furthermore, nurses are vulnerable to the illness, rumors, and incorrect data that increases their anxiety levels. ${ }^{[13]}$

The nurses who work in quarantine hotels and isolation departments inside Jeddah city, were distributed over 32 hotels and 5 isolation departments in the hospitals as of April 30, 2020. In isolation and quarantine nurses are working with an integrated team of health care providers and administrators. ${ }^{[14]}$

Globally, there is a lack of relevant research of pandemic respiratory diseases such as Middle East respiratory syndrome that can be used as lessons, experiences, and evidence to improve care. In Kingdom of Saudi Arabia, there is also a shortage of research that address this important and crucial subject.

This study focuses on nurses' conditions in quarantine and isolation during COVID-19 in Jeddah City. The author hoped that the outcomes of the study might raise the level of the care provided and inspire stakeholders to take action to improve nurses' conditions in quarantine and isolation.

The aim of the study was to identify the nurses' conditions in quarantine and isolation during COVID-19 in Jeddah City. The study objectives were to assess the nurses' conditions in quarantine and isolation during COVID-19, improve the nurses' conditions in quarantine and isolation during COVID19 , and provide lessons and experiences for current and future crises.

\section{METHODS}

\subsection{Study setting}

This study was carried out in isolation departments in selected hospitals and quarantine hotels that used to treat or monitor suspected or confirmed cases with COVID-19 in Jeddah city.

\subsection{Study subjects}

The nurses who work in quarantine hotels and isolation departments in Jeddah city.

\subsection{Study design}

This study used a cross-sectional descriptive design. 


\subsection{Study tool}

The questionnaire was sent to nurses who were working in isolation departments and quarantine hotels during COVID19 outbreak. The questionnaire includes four parts, the first and second parts were developed by the researcher based on literature review, first part about participants' demographic data and the second part was related to the participants of the study. The third part was adapted from COVID-19 Safety Guide for Health Care Nursing ${ }^{[15]}$ and Self-Assessment Tool for COVID-19 ${ }^{[16]}$ which focuses on nurses' assessment of quarantine and isolation conditions during COVID-19. While the fourth part was an open-ended question about nurses' suggestions that may help improve the current and future nursing conditions in isolation and quarantine.

\subsection{Sample size}

Sample size is 110 nurses.

\subsection{Inclusion criteria}

Nurses who work in quarantine hotels and isolation departments.

Nurses who provide direct care to suspected or confirmed cases with COVID-19.

\subsection{Exclusion criteria}

1) Nurses who are not working in quarantine hotels and isolation departments.

2) Nurses who are not providing direct care to suspected or confirmed cases with COVID-19.

\subsection{Sampling technique}

The study used a convenience sampling technique. Which is one type of non-probability sampling, lets the researcher choose the most reachable and accessible individuals as participants.

\subsection{Data collection}

Ethical approval was obtained from the Research Institutional Review Board (IRB)-Ministry of Health in Kingdom of Saudi Arabia. An informed consent was given to participants before they take a part in the study, confidentiality and privacy were implemented. Data were collected electronically.

\subsection{Data analysis}

The data were analyzed by using the Statistical Package for the Social Sciences (SPSS, version 24). Descriptive statistics were used. T-Test and One-Way Analysis of Variance (ANOVA) were used to examine if there are significant differences between the variables.

\subsection{Reliability and validity}

To obtain accurate information by the survey instrument, it is essential to make sure that, the constructed survey instrument is highly reliable and valid, as shown in Tables $1 \& 2$.

\subsection{Research instrument validity}

To measure the questionnaire validity and reliability the researcher conducted a pilot study by distributing the questionnaire among 20 nurses of the study population. Person's correlation coefficient has been used to measure the degree of association between each statement (item) included in the survey instrument, with the total scores of the dimension to which is related, and the results demonstrated as in Table 1.

Table 1. Survey instrument validity

\begin{tabular}{llll}
\hline Item No. & $\begin{array}{l}\text { Correlation } \\
\text { coefficient }\end{array}$ & Item No. & $\begin{array}{l}\text { Correlation } \\
\text { coefficient }\end{array}$ \\
\hline 1 & $0.776^{* *}$ & 6 & $0.736^{* *}$ \\
2 & $0.693^{* *}$ & 7 & $0.631^{* *}$ \\
3 & $0.647^{* *}$ & 8 & $0.501^{* *}$ \\
4 & $0.581^{* *}$ & 9 & $0.745^{* *}$ \\
5 & $0.603^{* *}$ & 10 & $0.849^{* *}$ \\
\hline **Correlation is significant at the (0.01) level.
\end{tabular}

Table 1 reveals that, there is a statistically significant correlation relationship between the score of each statement included in the survey instrument, with the total scores of the survey instrument. Meaning that, all statements achieve the purpose of measurement that support the validity of the questionnaire.

\subsection{Research instrument reliability}

To assess the survey instrument reliability, the Cronbach's Alpha coefficient has been calculated, to find the internal consistency of all items, and the results demonstrated as in Table 2.

Table 2. Survey instrument reliability (internal consistency)

\begin{tabular}{lll}
\hline & No. of items & Cronbach' Alpa \\
\hline Overall reliability & 10 & 0.869 \\
\hline
\end{tabular}

The results in Table 2, show that, the overall reliability of the questionnaire method measured by Cronbach's Alpha is reaching (0.869) which is highly sufficient to justify the reliability of the questionnaire method, and its suitability to collect the needed data.

\section{RESULTS}

\subsection{Part 1}

Sociodemographic data of the participants are summarized in Table 3, the results indicate that the majority of $60 \%$ are in the age class (30-39) years, where only $2.7 \%$ in the age group 
(50-59). Hence most nursing staff who participated in the current study are at the age of youth. While the respondents' distribution by gender, the female nurses comprised the majority of $80.0 \%$, while males represent only $20 \%$. Therefore, female nursing overestimates the male. Furthermore, the results, reveal that the married comprised the majority by $60.9 \%$, whereas the widow and divorced show fewer percentages. The sample distribution by nationality, shows that Saudi nursing comprised the majority of $63.6 \%$, whereas Non-Saudi nurses represent about $36.4 \%$, as demonstrated in Table 3. On the other hand, the participants of the current study distribution by educational level, reveals that almost all nurses by $68.2 \%$ hold BSN as an educational level. Hence, the majority of nursing staff participants in the current study are university graduates. In addition to that, the participants' distribution by total years of experience reveals that nearly all respondents have total years of experience between (6-10) years. In terms of the nursing experience, the results show that most of the nursing participants in the current study with $52.7 \%$ have experience in critical care, while $13.6 \%$ have experience in the surgical or medical department, whereas 9.1\% their experience in the ER department, while $6.4 \%$ have experience in public health, where $18.2 \%$ have experience in other departments. Regarding, the participants' distribution according to the current place of work, $56.4 \%$ work at hospital isolation, whereas $43.6 \%$ work at quarantine. Additionally, the results found that most nursing staff with $64.5 \%$ have been employed in the civil service, while $35.5 \%$ have been employed in the operational programs. Thus, almost all respondents have been employed in the civil service system.

\subsection{Part 2}

\subsubsection{Analysis of questions related to the participants of the study}

Figure 1 reveals that $65.5 \%$ of the participants had been assigned from work willingly, while $22.7 \%$ of them had been assigned from work unwillingly, only $11.8 \%$ confirmed that they work as volunteers.

Figure 2 reveals that $31.8 \%$ of the participants confirmed that they have been working in quarantine and isolation for less than a week, while $19.1 \%$ of the participants confirmed that they have been working in quarantine and isolation for one week to two weeks. $30 \%$ believe that they have been working for three weeks to a month, where $19.1 \%$ have been working in quarantine and isolation for more than a month.

Figure 3 illustrates that, $60.0 \%$ of the participants confirmed they have the willingness to continue working in quarantine and isolation, while $40.0 \%$ are unwilling to continue working in quarantine and isolation. Hence, almost all the nursing participants of the current study show that they are willing to

Published by Sciedu Press continue working in quarantine and isolation.

Table 4 shows that among the most important reasons that make nursing participants of the current study to be unwilling to continue working in quarantine and isolation, are the lack of rewards and incentives by $28.3 \%$, unsafe work environment $40.0 \%$, and long working hours $10.0 \%$.

Table 3. Participants distribution by demographic characteristics $(n=110)$

\begin{tabular}{|c|c|c|}
\hline Demographic profile & Frequency & Percent $\%$ \\
\hline \multicolumn{3}{|l|}{ 1. Age } \\
\hline $20-29$ & 27 & 24.5 \\
\hline $30-39$ & 66 & 60.0 \\
\hline $40-49$ & 14 & 12.8 \\
\hline $50-59$ & 3 & 2.7 \\
\hline \multicolumn{3}{|l|}{ 2. Gender } \\
\hline Male & 22 & 20.0 \\
\hline Female & 88 & 80.0 \\
\hline \multicolumn{3}{|l|}{ 3. Marital Status } \\
\hline Married & 67 & 60.9 \\
\hline Single & 38 & 34.5 \\
\hline Widow & 3 & 2.7 \\
\hline Divorced & 2 & 1.8 \\
\hline \multicolumn{3}{|l|}{ 4. Nationality } \\
\hline Saudi & 70 & 63.6 \\
\hline Non-Saudi & 40 & 36.4 \\
\hline \multicolumn{3}{|l|}{ 5. Educational level } \\
\hline Diploma & 25 & 22.7 \\
\hline BSN & 75 & 68.2 \\
\hline Master & 10 & 9.1 \\
\hline \multicolumn{3}{|l|}{ 6. Total Years of experience } \\
\hline $1-5$ years & 25 & 22.7 \\
\hline $6-10$ & 46 & 41.8 \\
\hline $11-15$ & 21 & 19.1 \\
\hline $16-20$ & 13 & 11.8 \\
\hline $21-25$ & 2 & 1.8 \\
\hline 26 years and more & 3 & 2.7 \\
\hline \multicolumn{3}{|l|}{ 7. Nursing experience } \\
\hline ER department & 10 & 9.1 \\
\hline Surgical or medical care & 15 & 13.6 \\
\hline Critical care & 58 & 52.7 \\
\hline Public health & 7 & 6.4 \\
\hline Other & 20 & 18.2 \\
\hline \multicolumn{3}{|l|}{ 8. Current place of work } \\
\hline Hospital Isolation & 62 & 56.4 \\
\hline Quarantine & 48 & 43.6 \\
\hline \multicolumn{3}{|l|}{ 9. Employment systems } \\
\hline Employment in the civil service & 71 & 64.5 \\
\hline Employment in operational program & 39 & 35.5 \\
\hline
\end{tabular}




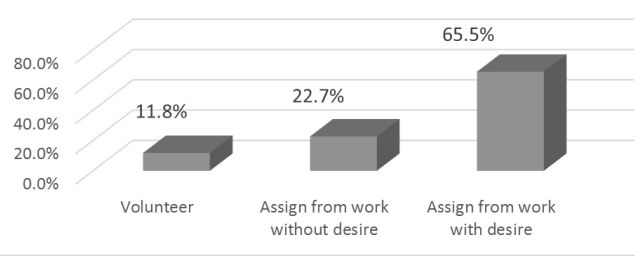

Figure 1. Participants' responses related to their assignment in quarantine and isolation

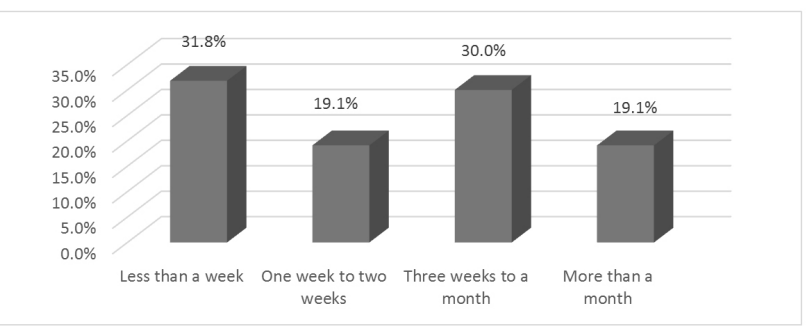

Figure 2. Participants' responses regarding how long they work in quarantine and isolation

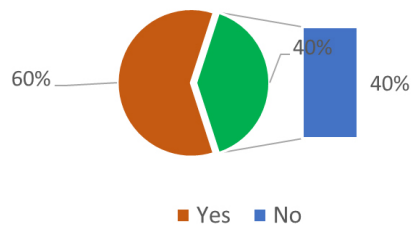

Figure 3. Participants' responses regarding if they are willing to continue working in quarantine and isolation

Table 4. Participants' reasons regarding if they are unwilling to continue working in quarantine and isolation

\begin{tabular}{lll}
\hline & Frequency & Percent\% \\
\hline No staff accommodation & 5 & 4.5 \\
Lack of rewards and incentives & 31 & 28.3 \\
Long working hours & 11 & 10.0 \\
Lack of effective teamwork & 1 & 0.9 \\
Unsafe work environment & 44 & 40.0 \\
Pregnancy & 3 & 2.7 \\
All the above & 4 & 3.6 \\
Other & 11 & 10.0 \\
Total & 110 & 100.0 \\
\hline
\end{tabular}

Table 5 shows that among the most important reasons that make nursing participants of the current study willing to continue working in quarantine and isolation are safe working environment by $37.3 \%$, effective teamwork by $31.8 \%$, availability of staff accommodation by $13.6 \%$, and appropriate rewards and incentives by $12.8 \%$.

\subsection{Part 3}

The results in Table 6 , show that the overall mean value of the participants' responses regarding their assessment of quaran- tine and isolation conditions during COVID-19 is reaching 3.23 with SD 0.67 , which indicates that the majority of participants confirmed that they often have a positive assessment. The detailed analysis of participants is presented as follows: Regarding statement No.5, stated that (Easy for you to report to supervisor if you are experiencing any signs of illness) the mean value to their responses is equal to 3.59 with SD 0.79 . This mean value indicates that most nurses' participants in the study confirmed that it is always easy for them to report to their supervisor if they are experiencing any signs of illness. Furthermore, regarding the statement No.7, (i.e. Report to the immediate supervisor if any situation observed with reasonable imminent and danger to life or health). The results show that the mean value is equal to 3.53 with SD 0.82 , which indicates that the majority of participants think that they always report to the immediate supervisor. Meaning that most of the nursing staff understand the importance of urgent reporting to the immediate supervisor to control any danger for life or health. While when participants show their responses to the statement No.8, (i.e. Follow your institution policies and recommendations regarding the use or reuse of PPE). The results show that the mean value is equal to 3.35 with SD (1.02). This indicates that most participants confirmed that they always follow their institutional policies and recommendations in regarding the use or reuse of PPE. This result confirms that most nurses understand the importance of following their institutions' policies and recommendations.

Table 5. Participants' perceptions regarding the reasons why they are willing to continue working in quarantine and isolation

\begin{tabular}{lll}
\hline & Frequency & Percent \% \\
\hline Availability of staff Accommodation & 15 & 13.6 \\
Appropriate rewards and incentives & 14 & 12.8 \\
Suitable working hours & 3 & 2.7 \\
Effective teamwork & 35 & 31.8 \\
Safe working environment & 41 & 37.3 \\
Other & 2 & 1.8 \\
Total & 110 & 100.0 \\
\hline
\end{tabular}

In addition to that, the results in Table 6, concerning the statement No.10, stated that (Care for suspected or confirmed people of COVID-19 is provided in an integrated manner covering all disciplines) found that the mean value of the participants' responses is equal to (3.23) with SD (1.04). The mean value indicates that the care for suspected or confirmed people of COVID-19 is provided in an integrated manner covering all disciplines.

On the other hand, the results in Table 6, regarding the statement No.9 (You received clear, scientific and up to date information about the COVID-19 pandemic from supervi- 
sor), it is clear that the overall mean value is reaching (3.19) with SD (1.06). This mean value indicates that almost all nurses' participants of the study confirmed that they often receive clear, scientific, and up to date information about the COVID-19 pandemic from the supervisor.

In addition to that, with regard to the participants' responses related to statement No.4 that stated (There are adequate infection prevention and control (IPC) and personal protective equipment (PPE) supplies (e.g., masks, N95 masks, gloves, goggles, gowns, hand sanitizer, soap and water, cleaning supplies in sufficient quantity) the results reveal that the overall mean value is equal to 3.17 with SD 0.88 . Thus, we conclude that nearly all the nurses' participants of the study agree that there are adequate infection prevention and control, and there are personal protective equipment supplies in sufficient quantity.

Table 6. Nurses assessment of quarantine and isolation conditions during COVID-19

\begin{tabular}{|c|c|c|c|c|c|c|c|c|c|}
\hline No. & Item & & Always & Often & $\begin{array}{l}\text { Some } \\
\text { Times }\end{array}$ & Never & Mean & SD & Ranking \\
\hline \multirow[b]{2}{*}{1} & \multirow{2}{*}{$\begin{array}{l}\text { There is a policy, guideline, or clear procedure } \\
\text { on how to handle the suspected or confirmed } \\
\text { cases of COVID- } 19 \text {. }\end{array}$} & $\mathrm{F}$ & 55 & 19 & 27 & 9 & \multirow[b]{2}{*}{3.09} & \multirow[b]{2}{*}{1.04} & \multirow[b]{2}{*}{8} \\
\hline & & $\%$ & 50.0 & 17.3 & 24.5 & 8.2 & & & \\
\hline \multirow{2}{*}{2} & \multirow{2}{*}{$\begin{array}{l}\text { You received instructions and training on } \\
\text { occupational safety and up to date. }\end{array}$} & $\mathrm{F}$ & 49 & 26 & 24 & 11 & \multirow{2}{*}{3.03} & \multirow{2}{*}{1.04} & \multirow{2}{*}{9} \\
\hline & & $\%$ & 44.5 & 23.6 & 21.8 & 10.0 & & & \\
\hline \multirow{2}{*}{3} & \multirow{2}{*}{$\begin{array}{l}\text { You received instructions and training in } \\
\text { infection control and personal protection } \\
\text { equipment that allowed to handle the suspected } \\
\text { or confirmed cases of COVID-19. }\end{array}$} & $\mathrm{F}$ & 58 & 17 & 24 & 11 & \multirow{2}{*}{3.11} & \multirow{2}{*}{1.07} & \multirow{2}{*}{7} \\
\hline & & $\%$ & 52.7 & 15.5 & 21.8 & 10.0 & & & \\
\hline \multirow[b]{2}{*}{4} & \multirow{2}{*}{$\begin{array}{l}\text { There is adequate infection prevention and } \\
\text { control (IPC) and personal protective equipment } \\
\text { (PPE) supplies (e.g., masks, N95 masks, gloves, } \\
\text { goggles, gowns, hand sanitizer, soap and water, } \\
\text { cleaning supplies) in sufficient amounts. }\end{array}$} & $\mathrm{F}$ & 49 & 35 & 22 & 4 & \multirow[b]{2}{*}{3.17} & \multirow[b]{2}{*}{0.88} & \multirow[b]{2}{*}{6} \\
\hline & & $\%$ & 44.5 & 31.8 & 20.0 & 3.6 & & & \\
\hline \multirow{2}{*}{5} & \multirow{2}{*}{$\begin{array}{l}\text { It is easy for you to report to supervisor if you are } \\
\text { experiencing any signs or symptoms of illness. }\end{array}$} & $\mathrm{F}$ & 82 & 15 & 9 & 4 & \multirow{2}{*}{3.59} & \multirow{2}{*}{0.79} & \multirow{2}{*}{1} \\
\hline & & $\%$ & 74.5 & 13.6 & 8.2 & 3.6 & & & \\
\hline \multirow[b]{2}{*}{6} & \multirow{2}{*}{$\begin{array}{l}\text { You seek management advice and support if you } \\
\text { are experiencing any signs of undue stress or } \\
\text { mental health challenges that require supportive } \\
\text { interventions. }\end{array}$} & $\mathrm{F}$ & 47 & 25 & 25 & 13 & \multirow[b]{2}{*}{2.96} & \multirow[b]{2}{*}{1.07} & \multirow[b]{2}{*}{10} \\
\hline & & $\%$ & 42.7 & 22.7 & 22.7 & 11.8 & & & \\
\hline \multirow[t]{2}{*}{7} & \multirow{2}{*}{$\begin{array}{l}\text { Report to the immediate supervisor if there is any } \\
\text { situation observed with reasonable imminent and } \\
\text { danger to life or health. }\end{array}$} & $\mathrm{F}$ & 77 & 18 & 11 & 4 & \multirow{2}{*}{3.53} & 0.82 & 2 \\
\hline & & $\%$ & 70.0 & 16.4 & 10.0 & 3.6 & & & \\
\hline 8 & Follow your institution policies and & $\mathrm{F}$ & 72 & 16 & 11 & 11 & 3.35 & 102 & 3 \\
\hline & recommendations in regards use or reuse of PPE. & $\%$ & 65.5 & 14.5 & 10.0 & 10.0 & & & \\
\hline 9 & $\begin{array}{l}\text { You received clear, scientific, and up to date } \\
\text { information about the COVID-19 pandemic from }\end{array}$ & $\mathrm{F}$ & 61 & 22 & 14 & 13 & 3.19 & 1.06 & 5 \\
\hline & supervisor. & $\%$ & 55.5 & 20.0 & 12.7 & 11.8 & & & \\
\hline & Care for suspected or confirmed people of & $\mathrm{F}$ & 63 & 20 & 16 & 11 & & & \\
\hline 10 & $\begin{array}{l}\text { COVID-19 is provided in an integrated manner } \\
\text { covering all disciplines. }\end{array}$ & $\%$ & 57.3 & 18.2 & 14.5 & 10.0 & 3.23 & 1.04 & 4 \\
\hline Ove & mean value & & & & & & 3.23 & 0.67 & \\
\hline
\end{tabular}

Furthermore, when participants of the current study provide their views regarding the statement No.2 (i.e. You received instructions and training in occupational safety and health using and up to date), the results in Table 6 , found that the overall mean value of the participants' responses is reaching 3.03 with SD 1.04. Therefore, it could be concluded that most nurses' participants thought that they often receive instructions and training in occupational safety and health using and up to date.

Finally, when respondents show their responses regarding the statement No.6 (i.e. Seek management advice and support if experiencing any signs of undue stress or mental health challenges that require supportive interventions), the results reveal that the mean value of the participants' perceptions is 2.96 with SD 1.07. Therefore, most participants feel that they sometimes seek management advice and support if experi- 
encing any signs of undue stress or mental health challenges that require supportive interventions.

\subsection{Testing significant differences}

This section is mainly devoted to examining whether there are statistically significant differences between participants' assessment of quarantine and isolation conditions during COVID-19, related to the demographic profile. First, to find significant differences, the researcher uses $t$-Test to examine the significant differences related to gender, nationality, current place of work, and employment systems. While One Way Analysis of Variance (ANOVA), was run to examine if there are significant differences related to age, educational level, and total years of experience.

The results in Table 7, reveal that the significant differences in participants assessment of quarantine and isolation conditions during COVID -19 exist only between the distribution of respondents according to the current place of work, and it is definite that the significant difference is positive to the side of the nurses who work at the quarantine.

Table 7. Results of $t$-test to examine significant differences in participants' assessment of quarantine and isolation conditions during COVID-19 related to gender, nationality, current place of work, and employment systems

\begin{tabular}{|c|c|c|c|c|c|c|}
\hline & Number & Mean & SD & Df & $t$-test & $p$-value \\
\hline \multicolumn{7}{|l|}{ 1. Gender } \\
\hline Male & 22 & 3.28 & 0.75 & \multirow{2}{*}{108} & \multirow{2}{*}{0.440} & \multirow{2}{*}{.66} \\
\hline Female & 88 & 3.21 & 0.65 & & & \\
\hline \multicolumn{7}{|l|}{ 2. Nationality } \\
\hline Saudi & 70 & 3.23 & 0.73 & \multirow{2}{*}{108} & \multirow{2}{*}{0.035} & \multirow{2}{*}{.972} \\
\hline Non-Saudi & 40 & 3.22 & 0.56 & & & \\
\hline \multicolumn{7}{|l|}{ 3. Current place of work } \\
\hline Hospital Isolation & 62 & 3.10 & 0.63 & \multirow{2}{*}{108} & \multirow{2}{*}{$-2.310^{*}$} & \multirow{2}{*}{.023} \\
\hline Quarantine & 48 & 3.39 & 0.88 & & & \\
\hline \multicolumn{7}{|l|}{ 4. Employment systems } \\
\hline Employment in the civil service & 71 & 3.30 & 0.63 & \multirow{2}{*}{108} & \multirow{2}{*}{1.681} & \multirow{2}{*}{.09} \\
\hline Employment in the operational program & 39 & 3.08 & 0.72 & & & \\
\hline
\end{tabular}

The results in Table 8, reveal that there are statistically significant differences in nurses' assessment of quarantine and isolation conditions during COVID-19 related to educational level.

To examine in which educational level the significant differences exist, multiple comparison analysis was conducted, as in Table 9.

Table 8. Results of analysis of variance to examine if there are significant differences in the assessment of quarantine and isolation conditions during COVID-19 related to the educational level

\begin{tabular}{llllll}
\hline \multicolumn{5}{c}{ ANOVA } \\
\hline \multicolumn{5}{c}{ Assessment of COVID-19 } \\
& $\begin{array}{l}\text { Sum of } \\
\text { Squares }\end{array}$ & & $\begin{array}{l}\text { Mean } \\
\text { Square }\end{array}$ & F & Sig. \\
\hline Between Groups & 2.752 & 2 & 1.376 & $3.203^{*}$ & .045 \\
Within Groups & 45.976 & 107 & .430 & & \\
Total & 48.729 & 109 & & & \\
\hline *indicated that the differe is significant at the (0.05) & & & \\
\hline
\end{tabular}

*indicated that the difference is significant at the (0.05) level.
Table 9. Results of multiple comparison analysis to determine in which educational level the difference exist

\begin{tabular}{lllll}
\hline \multirow{2}{*}{ Education level } & \multirow{2}{*}{$\begin{array}{l}\text { Mean } \\
\text { value }\end{array}$} & \multicolumn{3}{l}{ Mean difference } \\
\cline { 3 - 5 } & 3.48 & Diploma & BSN & Master \\
\hline Diploma & 3.18 & - & - & $0.57^{*}$ \\
BSN & 2.91 & $-0.57^{*}$ & - & - \\
Master & & & -
\end{tabular}

*The results of multiple comparison analysis in Table 9, show that the significant difference exists between respondents who hold a diploma, compared with those who hold master, which is positive to the side of diploma holders.

\section{DiscuSSiON}

The study reveals that around $60 \%$ of the nursing staff confirmed that they have the willingness to continue working in quarantine and isolation, and about $40 \%$ do not have the will to continue working in those conditions. Similar to our finding, a previous study about the $\mathrm{H} 1 \mathrm{~N} 1$ pandemic found that $86 \%$ of nurses were willing to work during the flu pandemic. ${ }^{[17]}$ 
Table 10. Participants suggestions regarding improving nursing conditions in isolation and quarantine that can help improve the current and future situations

\section{Nurses' suggestions for nurses conditions improvement:}

- $\quad$ Please consider pregnant staff and nurses with weak immunity.

- $\quad$ Provide additional training related to COVID-19 handling or exposed and infection control precautions.

- $\quad$ Provide psychological support for the frontline staff or other hospital staff to reduce anxiety and increase fairness between health care workers.

- $\quad$ Kindly support the nurse's family financially if a nurse's death happened due to COVID-19.

- Consider personal problems and allow them as genuine excuses.

- Do not neglect staff members who are in isolation or quarantine; please support them psychologically. Fight for your nurses.

- $\quad$ Appreciate and respect every nurse and provide appropriate rewards and incentives to all nurses.

- $\quad$ Provide accommodations and meals to reduce nurses' moving around the hospital and restrict the spread of infection.

- Properly assess staff members, especially in a staff clinic, regardless of their condition; and give sick leave if needed to avoid the spread of the virus amongst colleagues and others; and do not underestimate the symptoms staff members are experiencing.

- $\quad$ Require nurses assigned to COVID-19 patients to be quarantined, including swab and fitness tests after completing their work with suspected or confirmed cases of COVID-19; N95masks should be available for each staff member.

- $\quad$ Provide an infection allowance for all staff members handling or exposed to COVID-19.

- $\quad$ Give an extra salary.

- Lessen the duty hours, provide the proper amount of time off for rest, and allow breaks.

- $\quad$ Provide an isolation allowance to all nursing staff.

\section{Nurses' suggestions for quarantine and isolation improvement:}

- Strictly follow the admission criteria because quarantine areas are not as well-prepared as isolation areas in hospitals, especially for high-risk patients. Because each patient is locked in a separate room, nurses cannot always attend to them because of this limitation.

- Bring an active team from public health or infection control to follow up with us if there is any update about COVID-19 or any infectious diseases.

- $\quad$ Provide adequate PPE for the staff and patients' safety because we do not have enough. We always get one or two gowns and 10 pairs of gloves. This is not enough for us; kindly consider our safety as well.

- $\quad$ Create stable and unified policies for dealing with and handling people with COVID-19 in quarantine.

- Maintain collaboration between all departments-not only nurses-facing patients who need psychological, social, and medical care.

- Minimize working hours and special staff working for the isolation patients; it is better to assign them as they wish and not by force (Risk allowance).

- $\quad$ Provide adequate nursing staff (staff sufficiency) to handle patients, so working hours do not exceed 8 hours.

- Separate isolation rooms from other clean patients and place them on a separate floor.

- $\quad$ Provide areas for nurses to wash and get dressed in the workplace and the ability to use different uniforms at work.

3. Nurses' suggestions for disease-outbreak-related readiness:

- $\quad$ Require hospital leaders and individual departments like nursing administration and infection control to prepare a readiness plan as published by WHO to prevent outbreaks and include it in the organization's strategic plan.

- Maintain communication daily and update the staff about everything going on.

- $\quad$ Provide backup plans for any possible disasters and train personnel for these plans.

- Have a definite plan and protocol in place for pandemic cases like these. Times like this need intensive and multidisciplinary teamwork amongst health workers. Nurses should always receive up-to-date information and training, so they are prepared to readily face unexpected events like this.

- Keep the staff aware of this study's outcomes and results to improve health care.

- Encourage the permanent participation of nursing personnel in scientific nursing research and give them the opportunity to participate.

The results of the present study found that among the most significant reasons that prohibit nursing staff from continuing to work in quarantine and isolation are lack of rewards and incentives, unsafe work environment, and long working hours. Furthermore, we found that among the most important reasons that encourage nursing staff to have the willingness to continue working in isolation and quarantine include safe working environment, effective teamwork, and availability of 
staff accommodation. This has been somewhat agreed upon in studies that found recognition from the health authorities, social and moral responsibilities, professional obligations, physical safety against infection, and trust amongst organizations and staff are valuable elements in workers being willing to work during a crisis. ${ }^{[18,19]}$

The results of the current study reveal that many indications show that nursing participants have demonstrated a positive assessment of quarantine and isolation during COVID-19. Most of the participants believe that it is easy for them to report to a supervisor if they experience signs of illness, and they always report to the immediate supervisor if any situation presents an imminent and severe danger to life or health. A similar pattern of results was obtained from a previous study that showed $53.8 \%$ of the participants reported to their supervisors during the influenza pandemic. Increased possibility of reporting may relate to the ability to communicate effectively in the organization. ${ }^{[20]}$

The results of the study show that the majority of nursing staff think that there are infection prevention and control and PPE supplies in sufficient quantity and that they always follow their institutions' policies and recommendations in regards to use, extended use, or reuse of PPE. This is in line with the authors of a previous study who found that during serious emerging infections, such as COVID-19, clear and unified policies are available for health care workers about the use of PPE. ${ }^{[21]}$

On the other hand, the results in this study indicate that almost all participants confirmed that they often receive evident, scientific, and up-to-date information about the COVID19 pandemic. This result is consistent with the result of a previous study in which participants perceived sufficiency of information about several aspects of A/H1N1 influenza. ${ }^{[1]}$

Instructions and training in infection control and PPE play a prime role in lowering the risk of infection for nurses. ${ }^{\text {[22] }}$ Most nurse participants in this study believed that they often received adequate instructions and training that allowed them to provide care for patients with suspected or confirmed cases of COVID-19. This is consistent with Modi et al. ${ }^{[23]}$ who showed adequate awareness (71.2\%) of COVID-19 in the health care setting. However, they showed that there is a strong need for education and training programs on infection control practices for COVID-19.

Decision-makers in the health system must identify that nurses are at a high risk of psychological distress and should receive early psychological intervention and support. ${ }^{[24]}$ Therefore, most participants feel that they sometimes seek management advice and support if experiencing signs of un- due stress or mental health challenges that require supportive interventions. Staff support by supervisors and managers is needed to inspire staff participation in epidemic crises. Du et al. ${ }^{[25]}$ reached a similar result and suggested that frontline health workers should be closely monitored as a high-risk group for stress, depression, and anxiety, as well as given proper training about COVID-19 knowledge and stress management. Psychologically supportive advice may increase frontline nurses' resilience to stress and psychological symptoms during the COVID-19 outbreak.

A significant difference exists between nursing staff participants of the current study towards COVID-19 related to the current place of work, and it is clear that the difference is a positive to the side of nursing staff who work in quarantine. This means the nurses who work in quarantine have better conditions compared with those who work in isolation at a hospital.

In addition, the results of this study show that the educational level has an influence on participants' perceptions towards working in isolation with COVID-19 patients, compared with those who hold masters degrees, which is positive to the side of diploma holders. This indicates that the nursing staff who hold diplomas are at the frontline to deal with COVID-19.

\subsection{Limitations}

This study had some limitations in interpreting the findings because COVID-19 is a novel coronavirus and no research has been conducted with which to make comparisons. A convenience sampling technique was used to collect the data, meaning it does not include a random collection of data and is not representative of the population. The study sample was small. Therefore, the results of this study cannot be generalized.

\subsection{Recommendations}

Based on this study's results and participants' suggestions, the author has created these recommendations:

1) Create an awareness team and clarify their responsibilities in addition to their work following up on staff information. If there is any update about COVID-19 or any infectious diseases, management can assign this task to the public health or the infection control team or the nursing education department.

2) Provide a sufficient amount of personal protective equipment (PPE) to ensure the nurses' safety and the patients' health, following the international studies approved for calculating the PPE required for each nurse according to the number of cases and the nurses' working time.

3) Review, frequently update and distribute the organization's policies for dealing with and handling cases of COVID-19 
according to approved policies and guidelines.

4) Encourage effective teamwork and help nurses to focus on nursing tasks only.

5) Ensure decision-makers pay attention to the improvement of the working environment in hospital isolation areas.

6) Establish a preparedness plan and protocol for future pandemics based on the lessons learned from this pandemic.

7) Focus research on critical care preparedness, disasters, health crises, and disease outbreaks and how to plan for and manage them.

8) Encourage the nurses to specialize in critical care, disasters, and health crisis preparedness.

9) Provide psychological support because the advice may increase frontline nurses' resilience to stress and psychological symptoms during the COVID-19 outbreak.

10) Provide appreciation, rewards, and incentives for nurses working in hospital isolation areas.

11) Assess nurses' physical health properly, especially regarding COVID-19 symptoms, in the staff clinic or identify a specific clinic or department that nurses can communicate with about their symptoms and health. Build an appropriate plan for nurses for after they complete their work with suspected or confirmed cases of COVID-19, including quarantining them, taking swabs and so on.

12) Request that decision-makers approve an infection allowance for all staff nurses working in hospital isolation areas and give them more time off to rest.

\section{Conclusion}

In conclusion, this study showed that the majority of nurses who participated have demonstrated a positive assessment of their quarantine and isolation conditions during the COVID19 outbreak regarding significant issues such as receiving instructions, scientific and up-to-date information, training in infection control and the use of PPE and having adequate availability of PPE supplies and proper reporting systems and policies. These findings generally supported early preparedness for crises, including disease outbreaks, through planning, preparing policies and procedures, and qualifying nurses in crisis management and critical care to ensure good and prompt handling of any crisis. In addition, this study indicated a need to focus on studies that address crisis management involving epidemic diseases to utilize their findings to improve current and future situations.

\section{ACKNOWLEDGEMENTS}

I would like to thank Mrs. Eman Saeed Badokhon Director of Nursing Administration in Jeddah Provence for her support. My genuine thanks to my colleagues who are working in quarantine and isolation for their participation in this study and for their great effort in fighting COVID-19.

\section{CONFLicts OF INTEREST Disclosure}

The author declares that there is no conflict of interest.

\section{REFERENCES}

[1] Centers for Disease Control and Prevention. Discontinuation of Isolation for Persons with COVID-19 Not in Healthcare Settings (Interim Guidance). 2010. Available from: https://www.cdc.gov/coronavirus/2019-ncov/hcp/disp osition-in-home-patients.html

[2] World Health Organization. (2020). Coronavirus disease (COVID-19) Situation Report-120. Available from: https://www. who.int/do $\mathrm{cs} /$ default-source/coronaviruse/situation-reports/2 0200519-covid-19-sitrep-120.pdf?sfvrsn=515cabfb_2

[3] Centers for Disease Control and Prevention. Comprehensive Hospital Preparedness Checklist for Coronavirus Disease 2019 (COVID-19). last reviewed: March 25, 2020.

[4] World Health Organization. Considerations for quarantine of individuals in the context of containment for coronavirus disease (COVID19): interim guidance, 29 February 2020 (No. WHO/2019-nCov/IHR. Quarantine/2020.1). World Health Organization. 2010.

[5] Rosenbaum L. Facing Covid-19 in Italy-ethics, logistics, and therapeutics on the epidemic's front line. New England Journal of Medicine. 2020; 382(20): 1873-5. PMid:32187459 https://do i.org/10.1056/NEJMp2005492

[6] Cetron M, Landwirth J. Public health and ethical considerations in planning for quarantine. The Yale journal of biology and medicine. 2005; 78(5): 329 .

Published by Sciedu Press
[7] Kang L, Li Y, Hu S, et al. The mental health of medical workers in Wuhan, China dealing with the 2019 novel coronavirus. The Lancet Psychiatry. 2020; 7(3): e14. https://doi.org/10.1016/S221 5-0366 (20) 30047-X

[8] Brooks SK, Webster RK, Smith LE, et al. The psychological impact of quarantine and how to reduce it: rapid review of the evidence. The Lancet. 2020.

[9] Pfefferbaum B, North CS. Mental health and the Covid-19 pandemic. New England Journal of Medicine. 2020. PMid:32283003 https://doi.org/10.1056/NEJMp2008017

[10] Lee SM, Kang WS, Cho AR, et al. Psychological impact of the 2015 MERS outbreak on hospital workers and quarantined hemodialysis patients. Comprehensive psychiatry. 2018; 87: 123-7. PMid:30343247 https://doi.org/10.1016/j . comppsych. 20 18.10.003

[11] Goulia P, Mantas C, Dimitroula D, et al. General hospital staff worries, perceived sufficiency of information and associated psychological distress during the $\mathrm{A} / \mathrm{H} 1 \mathrm{~N} 1$ influenza pandemic. BMC infectious diseases. 2010; 10(1): 322. PMid:21062471 https: //doi.org/10.1186/1471-2334-10-322

[12] Makamure M, Makamure M, Mendiola W, et al. A review of critical care nursing and disease outbreak preparedness. Dimensions of Critical Care Nursing. 2013; 32(4): 157-61. PMid:23759903 https://doi.org/10.1097/DCC.0b013e318299801f 
[13] Schwartz J, King CC, Yen MY. Protecting healthcare workers during the coronavirus disease 2019 (COVID-19) outbreak: lessons from Taiwan's severe acute respiratory syndrome response. Clinical Infectious Diseases. 2020. PMid:32166318 https ://doi .org/10.109 $3 /$ cid/ciaa255

[14] Nursing Administration in Jeddah Region, Ministry of health in Saudi Arabia. Nursing Report. 2020.

[15] Saudi Patient Safety Center COVID-19 Safety Guide for Health Care Nursing. 2020.

[16] Central Board for Accreditation of Healthcare Institutes (CBAHI). Self-Assessment Tool for COVID-19. 2020.

[17] Martin SD. Nurses' ability and willingness to work during pandemic flu. Journal of Nursing Management. 2011; 19(1): 98-108. PMid:21223410 https : //doi .org/10.1111/j.1365-2834. 20 10.01190.x

[18] Jiang Y. Psychological impact and coping strategies of frontline medical staff in Hunan between January and March 2020 during the outbreak of Coronavirus Disease 2019 (COVID 19) in Hubei, China Med Sci Monit. 2020; 26: e924171. https ://doi.org/10.12659 /MSM. 924171

[19] Imai H. Trust is a key factor in the willingness of health professionals to work during the COVID-19 outbreak: Experience from the H1N1 pandemic in Japan 2009. Psychiatry and Clinical Neurosciences. 2020.
[20] Devnani M. Factors associated with the willingness of health care personnel to work during an influenza public health emergency: an integrative review. Prehospital and disaster medicine. 2012; 27(6): 551-66. PMid:23031432 https://doi.org/10.1017/S1049023 $\mathrm{X} 12001331$

[21] Chughtai AA, Seale H, Islam MS, et al. Policies on the use of respiratory protection for hospital health workers to protect from coronavirus disease (COVID-19). International Journal of Nursing Studies. 2020; 105: 103567. PMid:32203757 https://doi.org/10.1016/j.ij nurstu. 2020.103567

[22] Wang J, Zhou M, Liu F. Reasons for healthcare workers becoming infected with novel coronavirus disease 2019 (COVID-19) in China Journal of Hospital Infection. 2020; 105(1): 100-1. PMid:32147406 https://doi.org/10.1016/j.jhin.2020.03.002

[23] Modi PD, Nair G, Uppe A, et al. COVID-19 awareness among healthcare students and professionals in Mumbai metropolitan region: a questionnaire-based survey. Cureus. 2020; 12(4).

[24] Ho CS, Chee C, Ho R. Mental Health Strategies to Combat the Psychological Impact of Coronavirus Disease 2019 (COVID-19) Beyond Paranoia and Panic. Annals, Academy of Medicine, Singapore. 2020.

[25] Du J, Dong L, Wang T, et al. Psychological symptoms among frontline healthcare workers during COVID-19 outbreak in Wuhan. General Hospital Psychiatry. 2020. 